\title{
Meningoencephalitis and New Onset of Seizures in a Patient with Normal Brain CT and Multiple Lesions on MRI
}

José E. Vidal, Anne Spichler, Augusto C. P. de Oliveira and André Villela Lomar
Institute of Infectious Diseases Emílio Ribas, São Paulo, SP, Brazil

\begin{abstract}
Toxoplasmic encephalitis is the most common cerebral mass lesion in patients with AIDS. The definitive diagnosis requires direct demonstration of the tachyzoite form of Toxoplasma gondii in cerebral tissue. The presumptive diagnosis is based on serology, clinical and radiological features, and on response to anti-Toxoplasma therapy. Typically, patients have a subacute presentation of focal neurological signs, with multiple lesions in computed tomography (CT) or magnetic resonance imaging (MRI). However, the neurological and CT scan spectrum is broad. We report a case of toxoplasmic encephalitis in a heterosexual man without prior history of HIV infection. He was admitted with four days of headache, confusion, and new onset of seizures. His brain CT disclosed no alterations and MRI revealed multiple lesions. Empirical specific antiToxoplasma therapy was initiated and the patient experienced excellent clinical and radiological improvement. His HIV tests were positive and the $\mathrm{CD}_{4}^{+}$cell count was 74 cells $/ \mathrm{ml}(8.5 \%)$. On follow up, three months later, the general state of the patient was good, without neurological sequelae and with a normal MRI. We concluded that toxoplasmic encephalitis should be considered in the differential diagnosis of meningoencephalitis in sexually active individuals, including cases without prior history or suspicion of HIV infection, and no abnormalities on CT scan.

Key Words: Toxoplasmic encephalitis, computadorized tomography, magnetic resonance imaging, acquired immunodeficiency syndrome.
\end{abstract}

Toxoplasmosis is a parasitic disease that is prevalent worldwide and the majority of primary cases are asymptomatic. Toxoplasmic encephalitis (TE) is the most common cerebral mass lesion in patient with acquired immunodeficiency syndrome (AIDS) [1], and is due to reactivation of latent infection as a result of progressive loss of celular immunity. Most patients (>80\%) who develop disease have $\mathrm{CD}_{4}$ cell counts of $<100 \mathrm{cell} / \mathrm{mL}$ [2]. The frequency of TE in AIDS patients varies from about one fourth to one half of cases in the absence of antimicrobial prophylaxis [3].

Received on 08 September 2003; revised 23 February 2004.

Address for correspondence: Dr. José E. Vidal. Rua Capote Valente 668, Apto 78, Zip code: 05409-002, São Paulo, SP, Brazil. E-mail: jbermudez@emilioribas.sp.gov.br. Phone: (55 11) 95888756. Fax: (55 11)3088-3602.

The Brazilian Journal of Infectious Diseases 2004;8(1):115-117 (C) 2004 by The Brazilian Journal of Infectious Diseases and Contexto Publishing. All rights reserved.
We present a case of TE, as the first diagnosis of opportunistic infection in a patient with human immunodeficiency virus (HIV) infection, with normal brain computed tomography (CT) and multiple lesions on magnetic resonance imaging (MRI).

\section{Case Report}

A 49-year-old heterosexual man, without history of intravenous drug use, from Sao Paulo, presented to the hospital with four days of headache, confusion, and new onset of seizures. The patient denied having any other neurological signs or symptoms and any significant medical past history. The findings of a physical examination were grade III right-side hemiparesis with accentuated deep tendon reflexes, and nuchal rigidity. Cranial nerve and ophthalmoscopic examinations were normal. An urgent brain CT (Figure A) scan with and without contrast was normal and eletroencephalogram 


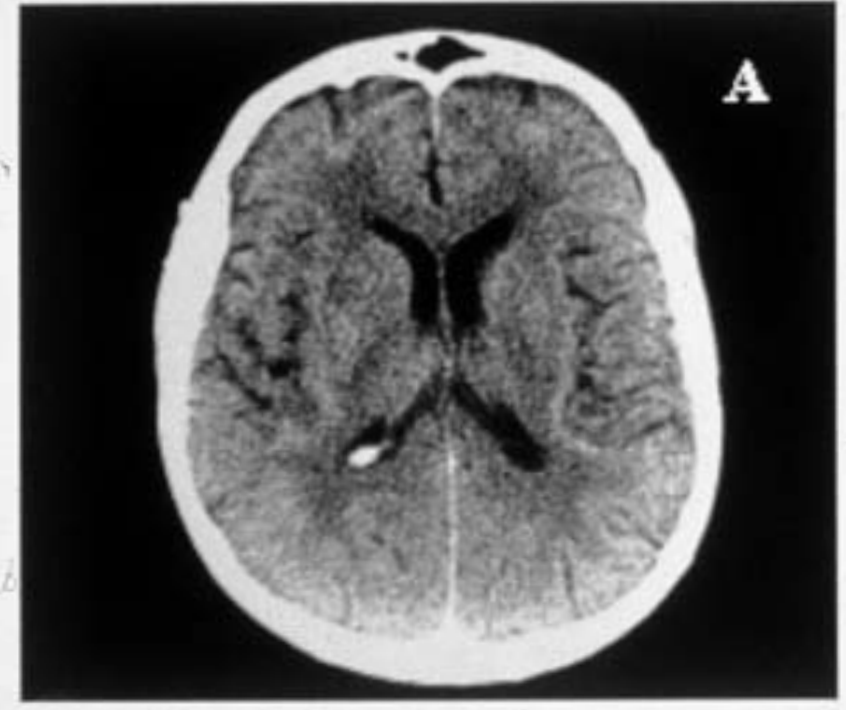

Figure A. CT scan with contrast material enhancement showed no abnormalities

disclosed diffuse endocephalitis. Laboratory evaluation showed anemia and lymphocytopenia. A lumbar puncture was performed and the cerebrospinal fluid (CSF) revealed 147 cells $/ \mathrm{mL}$ (4\% neutrophils, $87 \%$ lymphocytes, $8 \%$ monocytes, $1 \%$ eosinophils), a protein level of $108 \mathrm{mg} / \mathrm{dL}$, and a glucose level of $65 \mathrm{mg} / \mathrm{dL}$. Gram stain, culture and latex agglutunation for bacteria were all negative. A cerebral MRI (Figure B) demonstrated multiple focal lesions. On the second day of hospitalization he had another seizure and was lethargic and hemiplegic. The patient was transfered to the Intensive Care Unit and empirical treatment for toxoplasmic encephalitis with pyrimetamine, sulfadiazine, and acid folinic was initiated. The results of a serum enzyme-linked immunoabsorbent assay (ELISA) test and Western Blot for HIV were positive. The titres of serum ELISA test for $T$. gondii were high (> $250 \mathrm{UI} / \mathrm{mL})$, and the $\mathrm{CD}_{4}^{+}$ cells count was 74 cells $/ \mathrm{ml}(8.5 \%)$. After two weeks of treatment the patient had complete neurological recovery and partial resolution on MRI.

On follow up, three months later, the general state of the patient was good, without neurological sequelae

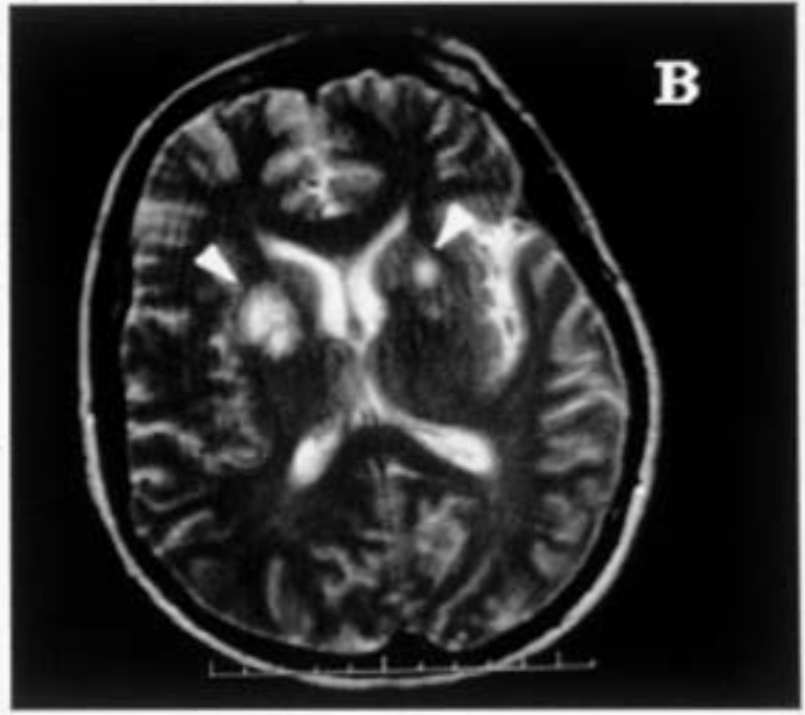

Figure B. Corresponding T2 weighted MRI showed multiple basal ganglia focal lesions, with high-intensity signals (arrows)

and normal MRI. He had 93 cells/mL and was receiving zidovudine, lamivudine, nelfinavir, and secondary prophylaxis for T. gondii.

\section{Discussion}

The introduction of highly active antiretroviral therapy (HAART) led to decline in the incidence of toxoplasmosis [4] and in toxoplasmosis-associated deaths [5]. However, a recent study [6] showed a lack of change in the distribution of AIDS-defining opportunistic disease, including toxoplasmosis, during the periods before and after the introduction of HAART.

A wide range of clinical findings, including altered mental state, seizures, weakness, cranial nerve disturbances, sensory abnormalities, cerebellar signs, meningismus, movement disorders, and neuropsychiatric manifestations are seen in TE [13]. The characteristic presentation usually has a subacute onset with focal neurologic abnormalities. However, in $15 \%$ to $25 \%$ of cases, the clinical course may be more abrupt, with seizures or cerebral hemorrhage. Aditionally, up $10 \%$ of patients may 
present with diffuse encephalitis, without any visible focal lesions [2]. Suspicion of TE in AIDS patients with neurological symptoms usually arises when neuroimaging studies demonstrate multiple lesions, but a solitary lesion may account for nearly one third of patients [7]. Toxoplamosis frequently affects the basal ganglia, although any portion of the brain may be envolved. Even when there are characteristic lesions on CT or MRI scanning, the findings are not patognomonic. The enhancing ring of toxoplasmosis lesions, when present, may be somewhat thicker and more ill defined than that seen in association with a typical bacterial abscess [8]. TE typically appears on CT and MRI as nodular (small encephalitis) and/or ringenhancing (large abscess-like lesions) lesions within the brain parenchyma. Nonenhancing lesions on CT have been reported in $6 \%$ to $20 \%$ of cases [3]. Increased dosages and delayed imaging increases the sensitivity of enhanced CT; however, MRI is more sensitive and will detect small additional lesions in some cases [3]. The finding of normal CT with abnormal MRI is rare, and has been reported in 3\% of cases (5 of 164 patients) [9]. One type of image that is highly suggestive of toxoplasmosis abscess is the assymetric target sign [7], a ring-shaped area of enhancement with a small excentric nodule along the wall of the enhancing ring, but it is seen in only a small percentage of cases.

The definitive diagnostic criteria of TE requires direct demonstration of the tachyzoite form of the parasite in brain tissue. Presumptive diagnosis is considered in patients with less than $200 \mathrm{CD}_{4}^{+} \mathrm{T}$-lymphocyte cells/ $\mathrm{mL}$, anti-Toxoplasma IgG antibody in the serum, consistent clinical features, characteristic neuroimaging studies, and response to empirical anti-Toxoplasma therapy [1-3]. Failure to respond to therapy after two weeks, indicated by persistence or worsening of either symptoms or the mass lesions observed on radiographic imaging dictates the need for a diagnostic stereotactic biopsy [10].

TE should be considered on differential diagnosis of cerebral focal lesions or diffuse encephalitis in young and sexually active patients, including cases without prior history or suspicion of HIV infection.

We concluded that TE has broad clinical and radiological features, complicating an initial diagnostic approach. If left untreated, it is often lethal, and if diagnosis is delayed, neurological sequelae will ensue. Only a high degree of suspicion led to early diagnosis and treatment, and consequently a good outcome.

\section{References}

1. Mamidi A., DeSimone J., Pomerantz RJ. Central nervous system infections in individuals with HIV-1 infection. J Neurovirol 2002;8:158-67.

2. Skiest D.J. Focal neurological disease in patients with acquired immmunodeficiency syndrome. Clin Infect Dis 2002;34:103-15.

3. Cohen B. Neurologic manifestations of toxoplasmosis in AIDS. Semin Neurol 1999; 19:201-11.

4. Abgrall S., Rabaud C., Costagliola D. Incidence and risk factors for toxoplasmic encephalitis in human immunodeficiency virus-infected patients before and during tha high active antiretroviral therapy era. Clin Infect Dis 2001;33:1747-55.

5. Jones J.L, Sehgal M., Maguire J.H. Toxoplasmosisassociated deaths among human immunodeficiency virus-infected persons in the United States, 1992-1998. Clin Infet Dis 2002;34:1161.

6. Manfredi R., Calza L., Chiodo F. Lack of change in the distribuition of AIDS-defining opportunistic diseases and the related degree of immunodeficiency during the periods before and after the introduction of highly active antiretroviral therapy. Eur J Clin Microbiol Dis 2001:20:410-3.

7. Ramsey R.G., Gean A.D. Central nervous system toxoplasmosis. Neuroimag Clin North Am 1997; 7:171-86.

8. Walot I., Miller B.L., Chang L., et al. Neuroimaging finding in patients with AIDS. Clin Infect Dis 1996;22:906-19.

9. Knobel H., Guelar A., Graus F., et al. Toxoplasmic encephalitis with normal CT scan and pathologic MRI. Am J Med 1995;99:220-1.

10. Report of the Quality Standards Subcommittee of the American Academy of Neurology. Neurology 1998;50:21-6. 